\title{
Lateral-Torsional Buckling of European Wide Flange I-Section Beams
}

\author{
Tolga Yilmaz, Nevzat Kirac, Turab Kilic \\ Eskisehir Osmangazi University \\ Department of Civil Engineering, 26480, Eskisehir, Turkey \\ tyilmaz@ogu.edu.tr; kiracn@ogu.edu.tr; kilicturab@gmail.com
}

\begin{abstract}
Lateral torsional buckling is one of the main failure modes in which the beam experiences non-uniform twisting and buckling about its weak axis. This study intends to describe lateral-torsional buckling behavior of European wide flange I-section beams. An analytical model based on Ritz method is established for doubly-symmeric I section by considering load position. A compact closed form equation which can be used for calculation critical elastic lateral-torsional buckling load of Europen wide flange I-section (HEA, HEB, HEM profiles) is developed using analytical solutions and dimensionless buckling parameters. The effects of slenderness and loading positions on lateral-torsional buckling behavior of beams with wide flange are investigated. The present solutions are validated with 1D finite element solutions in which beams are modeled with their exact geometries. Good agreement between the analytical and numerical solutions is demonstrated. It is concluded that the lateral-torsional buckling load of European HEA, HEB and HEM beams can be determined by presented method and can be safely used in design procedures.
\end{abstract}

Keywords: Steel, Stabilitiy, Lateral-torsional buckling, Finite Element Analysis, HEA, HEB and HEM profiles

\section{Introduction}

Lateral-torsional buckling (LTB) is one of the main failure modes controlling the strength of thin-walled structural members. Beams are mostly loaded in the plane of the weak axis so that bending occurs about their strong axis for economical use of structural material. Beams bending about its strong axis may buckle out of the plane by deflecting laterally and twisting as the values of the applied loads reach a limiting state. At this limiting state, the compression flange of the member becomes unstable and bends laterally while the remainder of the cross section, which is stable, tends to restrain the lateral flexure of the compression flange. The net effect is that the whole section rotates and moves laterally. The limit state of the applied loads on the structural members is called as the critical elastic LTB load. LTB failure occurs suddenly in slender thin-walled elements with a much greater in-plane bending stiffness than their lateral bending or torsional stiffnesses. LTB should be considered in design of slender beams, beam-columns and cantilevers with insufficient lateral bracing due to it may occur long before the bending stress at the extreme fiber of the section reaches to yield point. The cross section of the member, the unbraced length of the member, the support conditions, the type of loads acting on the member, the vertical positions of the applied loads with respect to shear center are effective on LTB behavior of beams and cantilevers.

The general concept of LTB and the solution of governing differential equation obtained for critical LTB load of beams subjected to uniform bending have been well presented in many textbooks [1]-[3]. LTB behavior are also studied using numerical approaches such as finite integral [4], [5], finite differences [6]-[10], finite elements [11]-[18] and finite strips methods [19]-[22] in case of different boundary conditions and load types where moment gradient is not constant because of the fact that analytical solutions are either too complex or involve infinite series. Energy method is based on the equality between the additional strain energy stored during LTB and the additional work done by the applied forces. The LTB load is calculated by substituting an approximate buckled shape which satisfies the kinematic boundary conditions and corresponds to real mode shape into the energy equation. Kinematic boundary conditions are related to geometrical constraints preventing one or more deflections or rotations at the support of the structural members [1]. Extensive studies are carried out in order to describe LTB behavior of thin-walled members using energy method. Aydin et al. [23] presented a compact closed-form equation to calculate LTB loads of simply supported beams with monosymmetric I-section. Mohri et al. [24] recomputed 3-factor formula, which is commonly used for calculation of elastic LTB loads of beams, and proposed some improvements. Ozbasaran et al. [25] developed an alternative design procedure for cantilever I-section and 
introduced a parametric formula based on energy method to calculate LTB load. The proposed design procedure was compared with code specifications and FEA. Kim et al. [26] studied LTB of castellated beams. The bracing stiffness requirements of monosymmetric I-beams with discrete torsional braces under pure bending condition was investigated Mohammadi et al. [27]. Non-linear stability model for LTB of beam-column elements with monosymmetric I-section including pre-buckling deflections are established by Mohri et al. [28]. Magnucka-Blandzi [29] investigated beam-columns with I-section subjected to a uniformly distributed transverse load, small axial force and two different moments located at its both ends. Stiffness reduction method for the flexural-torsional buckling assessment of steel beam-columns subjected to major axis bending and axial compression was examined by Kucukler et al. [30]. The flexural-torsional buckling of functionally graded open-section beams with various type of material were investigated by Nguyen et al. [31]. Chan [32] established a kinematic model based on energy method for tapered beam-columns. Yang and Yau [33] studied finite element model for beams that takes into consideration the effect of non-uniform torsion and geometric nonlinearity. Yuan et al. [34] developed an analytical model to determine LTB behavior of steel web tapered tee-section cantileves. Analytical solutions are validated with finite element analysis using Ansys sofware. Good agreement between analytical and numerical solutions is demonstrated. It is concluded that effect of web tapering on elastic LTB load of Tee-section cantilever depends on the flange witdth of the beam. A general variational model based on Ritz method including prebuckling deflection was introduced in order to analyze the LTB of monosymmetric and doubly symmetric tapered beams and cantilevers [35]-[38]. Benyamina et al. [39] introduced an analytical formula to assess LTB behavior of doubly symmetric web tapered I beams in function of the classical stiffness terms, the load height level and the tapering parameter.

In this study, LTB behavior of European wide flange I-section beams (HEA, HEB, HEM profiles) are investigated. A simplified closed-form equation which can be used for calculation of the elastic LTB loads of beams with wide flange are developed using Ritz method, dimensionless slenderness and load case parameter. Load case parameter are calculated for six load cases by considering three load positions which are top flange, shear center and bottom flange. Analytical solutions are validated with 1D finite element simulations. Beams are modeled with their exact geometries using LTBeamN software. Analytical solutions are in good accordance with numerical solutions. It is found out that the lateraltorsional buckling loads of European HEA, HEB and HEM beams can be determined by proposed technique.

\section{Analytical Method}

The LTB of beam consists of two stages. First, beam bends about its major axis, and then it buckles by bending laterally and twisting as the magnitude of the loads acting on the beam reaches to a critical level. Fig. 1 shows the LTB of beam with doubly-symmetric I-section subjected to concentrated force that acts transversely at midspan.

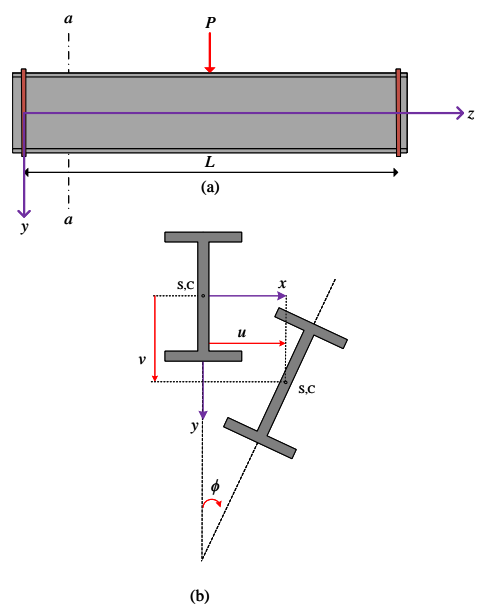

Fig. 1: LTB of doubly-symmetric beam (a) side view, (b) a-a section.

In Fig. 1 (a), L is the beam length. a-a section of the beam is drawn in Fig. 1 (b). S and $\mathrm{C}$ show the shear center and the center of gravity of the section, respectively. $\mathrm{u}$ is the lateral displacement of the shear center, $\mathrm{v}$ is vertical displacement of 
the shear center and $\varphi$ is torsional rotation. The strain energy stored in the beam due to lateral bending, warping and torsion can be calculated using the following formula [1]:

$$
U=\frac{1}{2} \int_{0}^{L} E I_{y}\left(\frac{d^{2} u}{d z^{2}}\right)^{2} d z+\frac{1}{2} \int_{0}^{L} E C_{w}\left(\frac{d^{2} \phi}{d z^{2}}\right)^{2} d z+\frac{1}{2} \int_{0}^{L} G J\left(\frac{d \phi}{d z}\right)^{2} d z
$$

Where $E$ is young modulus, $G$ is shear modulus, $I_{y}$ is the moment of inertia about the weak axis, $C_{w}$ is the warping constant and $J$ is the torsional constant.

The work done by the external transverse forces is as [1]:

$$
V=-\frac{1}{2} \int_{0}^{L} 2 M_{x} \phi\left(\frac{d^{2} u}{d z^{2}}\right) d z-\frac{1}{2} \sum P H_{p} \phi_{p}^{2}-\frac{1}{2} \int_{0}^{L} q H_{q} \phi^{2} d z
$$

Where $M_{x}$ is the bending moment about strong axis. The second and third terms in Eq. (2) are work done by concentrated $(P)$ and uniformly distributed loads $(q)$ which are acting outside of the shear center, respectively. Those works results from changing of the distance between the application points of the loads and the shear center as crosssection rotates. $H_{p}$ and $H_{q}$ are the vertical distance of the acting point of the concentrated and uniformly distributed loads measured from the shear center, respectively. $\phi_{p}$ is torsional rotation at a point in which the concentrated load is applied. In Eq. (2), $H_{p}$ and $H_{q}$ are positive for loads that act in below the shear center. Assume that when LTB occurs, the lateral displacement of beam defined at the shear center and the angle of rotation of the cross-section can be described as follows :

$$
\begin{aligned}
& u=A \sin \frac{\pi}{L} z \\
& \phi=B \sin \frac{\pi}{L} z
\end{aligned}
$$

Where $A$ and $B$ are the associated displacement amplitudes. Note that the dispalcement functions assumed in Eqs. (3)(4) satisfy the simply supported boundry conditions $\left(u=\phi=0\right.$ and $\left.d^{2} u / d z^{2}=d^{2} \phi / d z^{2}=0\right)$ at supports $(z=0$ and $z=L)$. The total potential energy $(\Pi=U+V)$ of the beam given in Fig 1, at a slightly buckled configuration can be written as following compact form by assuming that the vertical position of all transverse loads on the beam are same $\left(H_{p}=H_{q}=H\right)$ and substituting displacement functions in Eq. (1) and Eq. (2) :

$$
\Pi=\frac{\pi^{4} b^{2}}{4 L^{3}}\left[\frac{G J L^{2}}{\pi^{2}}+\frac{a^{2} E I_{y}}{b^{2}}+E C_{w}\right]+Z_{1} a b R_{c r}+Z_{2} b^{2} H R_{c r}
$$

In Eq. (5), $Z_{1}$ and $Z_{2}$ are integral parameters depending on moment gradient about strong axis along the beam length. In this study $Z_{1}$ and $Z_{2}$ are calculated for six load cases depicted in Fig 2. $R_{c r}$ is the critical load which can be expressed by Eq. (6) depending on the load type acting on the beam.

$$
R_{c r}=P_{c r}=q_{c r} L=\frac{M_{c r}}{L}
$$

Where $P_{c r}, q_{c r}$ and $M_{c r}$ are critical concentrated load, uniformly distributed load and moment, respectively. It is noted that the critical buckling load type varies according to considered loading case. For load case 3 in Fig. 2, the critical LTB load is in terms of $q_{c r}$ which implies that the critical values of uniformly distributed load and concentrated load are $q_{c r}$ and $0.5 q_{c r} L$, respectively. 

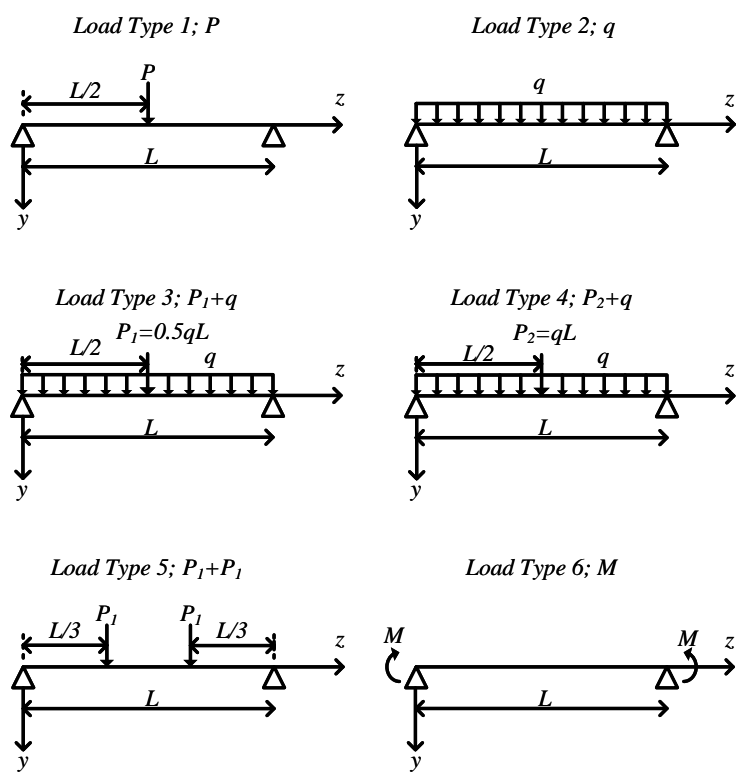

Fig. 2: Load cases.

Table 1: $\mathrm{Z}_{1}$ and $\mathrm{Z}_{2}$ integral parameters.

\begin{tabular}{|c|c|c|}
\hline Load Type & $\mathrm{Z}_{1}$ & $\mathrm{Z}_{2}$ \\
\hline $\mathrm{P}$ & -0.86685 & 0.5 \\
\hline $\mathrm{q}$ & -0.536234 & 0.25 \\
\hline $\mathrm{q}+0.5 \mathrm{qL}$ & -0.969659 & 0.5 \\
\hline $\mathrm{q}+\mathrm{qL}$ & -1.40308 & 0.75 \\
\hline $\mathrm{P}+\mathrm{P}$ & -1.47162 & 0.75 \\
\hline $\mathrm{M}$ & -4.9348 & 0 \\
\hline
\end{tabular}

When buckling occurs, the total energy function reaches to a stationary condition, which requires

$$
\frac{\partial \Pi}{\partial A}=\frac{\partial \Pi}{\partial B}=0
$$

Substituting Eq. (5) into Eq. (7) yields :

$$
\begin{gathered}
b Z_{1} R_{c r}+\frac{a E I_{y} \pi^{4}}{2 L^{3}}=0 \\
a Z_{1} R_{c r}+2 b Z_{2} H R_{c r}+\frac{\pi^{2} b}{2 L}\left(G J+\frac{\pi^{2} E C_{w}}{L^{2}}\right)=0
\end{gathered}
$$

Eq. (8) and Eq. (9) are standard eigen-value equations. The critical load can be calculated by considering the determinant of the coefficients matrix is equal to zero. Finally, LTB load of beam can be determined using following equation:

$$
R_{c r}=P_{c r}=q_{c r} L=\frac{M_{c r}}{L}=\frac{\pi^{4} E I_{y}}{2 Z_{1}^{2} L^{3}}\left[Z_{2} H \mp \sqrt{\left(Z_{2} H\right)^{2}+\frac{Z_{1}^{2} C_{w}}{I_{y}}\left(1+\frac{G J L^{2}}{\pi^{2} E C_{w}}\right)}\right]
$$

Eq. (10) can be also expressed as following compact form using dimensionless load case parameter $K_{L C}$ and considering $G=0,385 E$ for steel materials [40]. 


$$
R_{c r}=P_{c r}=q_{c r} L=\frac{M_{c r}}{L}=K_{L C} E\left(\frac{b t_{f}}{L}\right)^{2}
$$

$K_{L C}$ is a dimensionless coefficient, called as load case parameter, which depends on applied load type, the position of load respect to shear center and section properties. $K_{L C}$ of a beam which section properties are known can be obtained by using Eq. (10) and Eq. (11) for considered load case and load position. In this study, $K_{L C}$ parameters are calculated with respect to $S_{r}$, which is a dimesionless slenderness ratio given in Eq. (12), for six load cases shown in Fig. 2 by considering three different loading position that are top flange, shear center and bottom flange loading.

$$
S_{r}=\left(\frac{L t_{f}}{h b}\right)^{2}
$$

$S_{r}-K_{L C}$ curves are presented in Fig. (3) for European wide flange sections. However, $K_{L C}$ can be calculated more accurately by using Eq. (13).

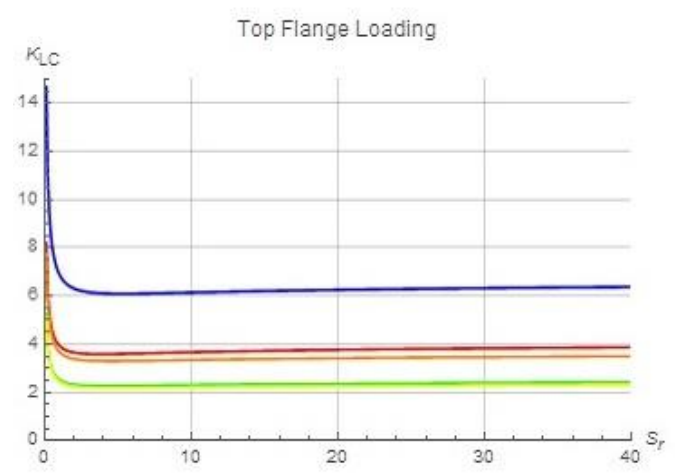

(a)

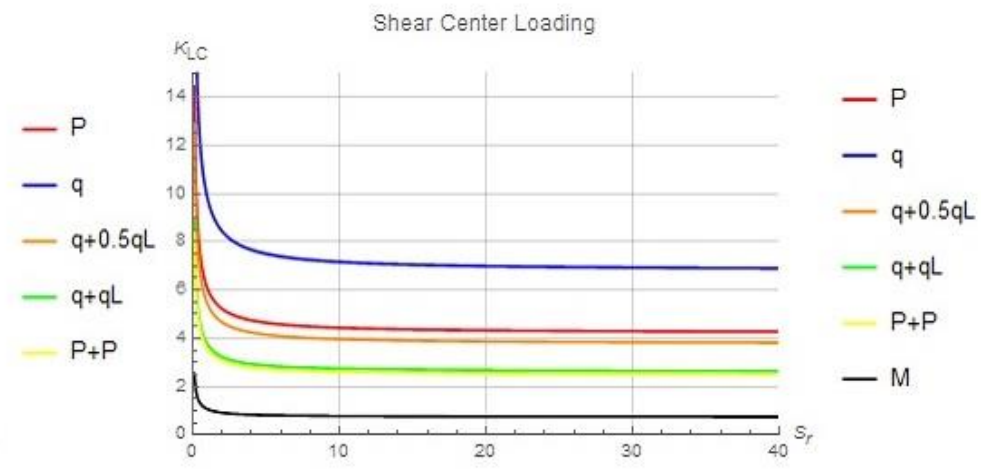

(b)

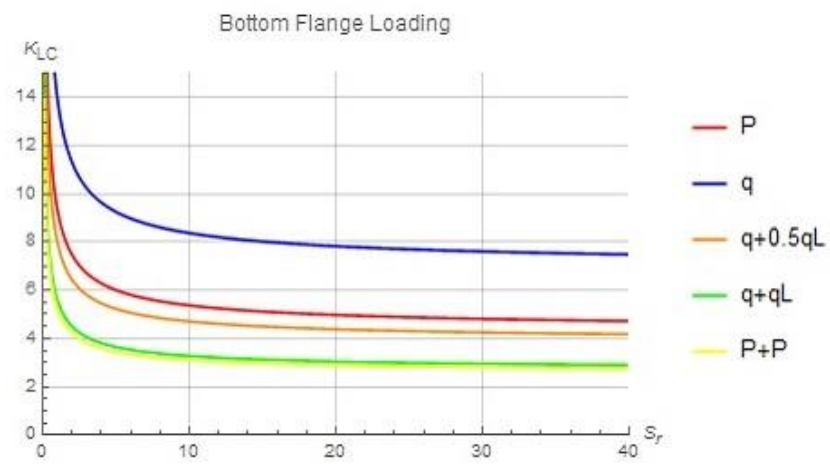

(c)

Fig. 3: $S_{r}-K_{L C}$ curves top flange (a), shear center (b), bottom flange (c).

$$
K_{L C}=a S_{r}{ }^{m}+b S_{r}{ }^{n}
$$

In Eq. (13), $a, b, m$ and $n$ are curve fitting constants. The values of the curve fitting constants can be obtained from Table 2 for considered load type and load positions in the limits $S_{r} \leq 10$ or $S_{r}>10$. 
Table 2: Curve fitting constants for European wide flange sections.

\begin{tabular}{|c|c|c|c|c|c|}
\hline \multirow[b]{2}{*}{$\begin{array}{l}\text { Load } \\
\text { Position }\end{array}$} & \multicolumn{5}{|c|}{$\mathrm{S}_{\mathrm{r}} \leq 10$} \\
\hline & $\begin{array}{l}\text { Load } \\
\text { Type }\end{array}$ & $\mathrm{a}$ & $\mathrm{b}$ & $\mathrm{m}$ & $\mathrm{n}$ \\
\hline \multirow{5}{*}{$\begin{array}{l}\text { Top } \\
\text { Flange }\end{array}$} & $\mathrm{P}$ & 2.4693091 & 1.4858447 & 0.1306704 & -0.6346488 \\
\hline & $q$ & 2.7070522 & 4.2115676 & -0.6283092 & 0.1184201 \\
\hline & $q+0.5 q L$ & 2.2755482 & 1.4168861 & 0.1237324 & -0.6313709 \\
\hline & $\mathrm{q}+\mathrm{qL}$ & 0.9594641 & 1.5582127 & -0.6324448 & 0.1258355 \\
\hline & $\mathrm{P}+\mathrm{P}$ & 1.5037082 & 0.9397269 & 0.1230723 & -0.6310183 \\
\hline \multirow{6}{*}{$\begin{array}{l}\text { Shear } \\
\text { Center }\end{array}$} & $\mathrm{P}$ & 2.9771823 & 3.1066508 & 0.0883374 & -0.5873335 \\
\hline & $q$ & 5.0220617 & 4.8127693 & -0.5873335 & 0.0883374 \\
\hline & $q+0.5 q L$ & 2.6615238 & 2.7772653 & 0.0883374 & -0.5873335 \\
\hline & $\mathrm{q}+\mathrm{qL}$ & 1.8393609 & 1.9193490 & 0.0883374 & -0.5873335 \\
\hline & $\mathrm{P}+\mathrm{P}$ & 1.8299563 & 1.7536936 & -0.5873335 & 0.0883374 \\
\hline & M & 0.5457162 & 0.5229737 & -0.5873335 & 0.0883374 \\
\hline \multirow{5}{*}{$\begin{array}{l}\text { Bottom } \\
\text { Flange }\end{array}$} & $\mathrm{P}$ & 6.7252056 & 2.6424210 & -0.5402802 & 0.1161904 \\
\hline & $\mathrm{q}$ & 9.5188065 & 4.4716986 & -0.5474445 & 0.1057909 \\
\hline & $\mathrm{q}+0.5 \mathrm{qL}$ & 5.5925213 & 2.4254496 & -0.5441228 & 0.1102070 \\
\hline & $q+q L$ & 3.9535132 & 1.6630534 & -0.5429043 & 0.1119968 \\
\hline & $\mathrm{P}+\mathrm{P}$ & 1.6020637 & 3.6583103 & 0.1096498 & -0.5445158 \\
\hline \multirow[b]{2}{*}{$\begin{array}{c}\text { Load } \\
\text { Position }\end{array}$} & \multicolumn{5}{|c|}{$\mathrm{S}_{\mathrm{r}}>10$} \\
\hline & $\begin{array}{l}\text { Load } \\
\text { Type }\end{array}$ & $\mathrm{a}$ & $\mathrm{b}$ & $\mathrm{m}$ & $\mathrm{n}$ \\
\hline \multirow{5}{*}{$\begin{array}{l}\text { Top } \\
\text { Flange }\end{array}$} & $\mathrm{P}$ & 3.3120118 & -0.0019120 & 0.0452441 & 0.8601901 \\
\hline & $\mathrm{q}$ & -0.0000031 & 5.7564719 & 2.0093953 & 0.0278056 \\
\hline & $q+0.5 q L$ & -0.0000954 & 3.0849611 & 1.3022547 & 0.0346929 \\
\hline & $\mathrm{q}+\mathrm{qL}$ & -0.0001888 & 2.1054844 & 1.1330332 & 0.0376861 \\
\hline & $\mathrm{P}+\mathrm{P}$ & -0.0000431 & 2.0406919 & 1.3646838 & 0.0337865 \\
\hline \multirow{6}{*}{$\begin{array}{l}\text { Shear } \\
\text { Center }\end{array}$} & $\mathrm{P}$ & 2.0631105 & 4.2110105 & -0.9627914 & 0.0003060 \\
\hline & $\mathrm{q}$ & 6.8073163 & 3.3351249 & 0.0003060 & -0.9627914 \\
\hline & $q+0.5 q L$ & 1.8443673 & 3.7645342 & -0.9627914 & 0.0003060 \\
\hline & $\mathrm{q}+\mathrm{qL}$ & 2.6016438 & 1.2746297 & 0.0003060 & -0.9627914 \\
\hline & $\mathrm{P}+\mathrm{P}$ & 2.4804735 & 1.2152644 & 0.0003060 & -0.9627914 \\
\hline & $\mathrm{M}$ & 0.7397087 & 0.3624073 & 0.0003060 & -0.9627914 \\
\hline \multirow{5}{*}{$\begin{array}{l}\text { Bottom } \\
\text { Flange }\end{array}$} & $\mathrm{P}$ & 4.4627933 & 4.9265841 & -0.0068403 & -0.6998030 \\
\hline & $\mathrm{q}$ & 7.1557048 & 6.8503280 & -0.0058810 & -0.7148212 \\
\hline & $q+0.5 q L$ & 3.9719102 & 4.0582296 & -0.0063187 & -0.7073367 \\
\hline & $\mathrm{q}+\mathrm{qL}$ & 2.7487780 & 2.8775243 & -0.0064820 & -0.7048245 \\
\hline & $\mathrm{P}+\mathrm{P}$ & 2.6159512 & 2.6520808 & -0.0062664 & -0.7081728 \\
\hline
\end{tabular}

At the end of the analytical study, it is concluded that the critical elastic LTB load of European wide flange beams can be determined in three steps. To perform this, first $S_{r}$ is calculated from section properties of the beam. Then, $K_{L C}$ can be found for considered loading case and loading position by Eq. (13). Finaly, the critical buckling load can be calculated by substituting $K_{L C}$ into Eq. (11).

\section{Numerical Analysis}

Effects of slenderness and load position on LTB behavior of HEA, HEB and HEM beams are studied in numerical study. Analytical solutions are compared to 1D finite element analysis where beams are modeled with their exact 
geometries using LTBeamN software. LTBeamN is capable of computing the elastic out-of-plane instability of both doubly-symmetric and mono-symmetric I-section beams by using an eigenvalue analysis. LTBeamN also can be used for tapered beams. Buckled shape of 1D beam model are depicted in Fig. (4).

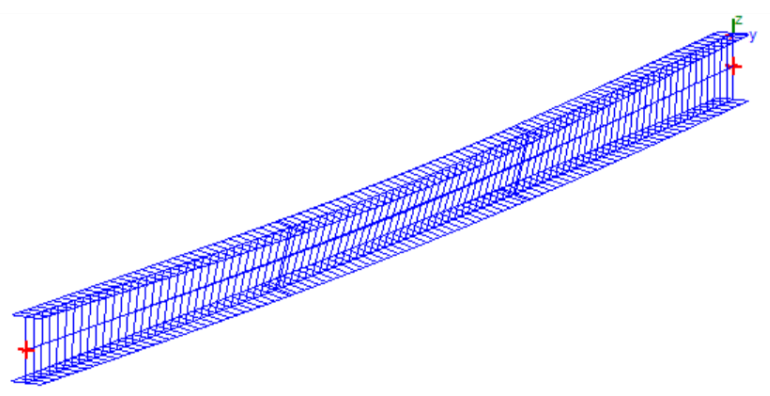

Fig. 4: Buckled shape of 1D beam model.

For six different load cases, six sections with different slendernesses were selected to compare the results. HEA100, HEB200, HEA300, HEB320, HEM360 and HEM240 sections were used for comparison of $\mathrm{P}, \mathrm{q}, \mathrm{q}+0.5 \mathrm{qL}, \mathrm{q}+\mathrm{qL}, \mathrm{P}+\mathrm{P}$ and $\mathrm{M}$ cases, respectively. Beams were loaded on their top flange, shear center and bottom flange to compare load position effect. The elastic LTB loads are calculated using Eq. (13) and LTBeamN 1D finite element model. Results are shown in Table (3) -(8) for load type 1-6, respectively. In Table (3)-(8), PE and LT are buckling loads obtained presented equation and LTBeamN software, respectively.

Table 3: LTB loads for load case 1.

\begin{tabular}{|c|c|c|c|c|c|c|c|c|c|}
\hline \multicolumn{10}{|c|}{ Load Case 1, P $(\mathrm{kN})$, HEA100 } \\
\hline $\mathrm{L}$ & \multicolumn{1}{|c|}{ Top Flange Loading } & \multicolumn{2}{c|}{ Shear Center Loading } & \multicolumn{3}{c|}{ Bottom Flange Loading } \\
\hline$(\mathrm{m})$ & PE & LT & PE/LT & PE & LT & PE/LT & PE & LT & PE/LT \\
\hline 2 & 115.165 & 117.580 & 0.98 & 158.824 & 161.020 & 0.99 & 219.133 & 219.000 & 1.00 \\
\hline 3 & 51.226 & 52.820 & 0.97 & 64.842 & 66.440 & 0.98 & 82.035 & 83.150 & 0.99 \\
\hline 4 & 29.638 & 30.330 & 0.98 & 35.505 & 36.300 & 0.98 & 42.612 & 43.250 & 0.99 \\
\hline 5 & 19.601 & 19.760 & 0.99 & 22.590 & 22.900 & 0.99 & 26.216 & 26.420 & 0.99 \\
\hline 6 & 14.056 & 13.920 & 1.01 & 15.735 & 15.770 & 1.00 & 17.857 & 17.800 & 1.00 \\
\hline 7 & 10.641 & 10.350 & 1.03 & 11.643 & 11.520 & 1.01 & 13.012 & 12.800 & 1.02 \\
\hline 8 & 8.376 & 7.999 & 1.05 & 8.994 & 8.793 & 1.02 & 9.944 & 9.646 & 1.03 \\
\hline 9 & 6.789 & 6.370 & 1.07 & 7.177 & 6.932 & 1.04 & 7.874 & 7.529 & 1.05 \\
\hline 10 & 5.630 & 5.193 & 1.08 & 5.872 & 5.605 & 1.05 & 6.407 & 6.040 & 1.06 \\
\hline
\end{tabular}

Table 4: LTB loads for load case 2.

\begin{tabular}{|c|c|c|c|c|c|c|c|c|c|}
\hline \multicolumn{10}{|c|}{ Load Case 2, q $(\mathrm{kN} / \mathrm{m})$, HEB200 } \\
\hline $\mathrm{L}$ & \multicolumn{2}{|c|}{ Top Flange Loading } & \multicolumn{2}{c|}{ Shear Center Loading } & \multicolumn{3}{c|}{ Bottom Flange Loading } \\
\hline$(\mathrm{m})$ & PE & LT & PE/LT & PE & LT & PE/LT & PE & LT & PE/LT \\
\hline 2 & 1759.527 & 1739.700 & 1.01 & 2613.468 & 2577.100 & 1.01 & 3881.386 & 3772.700 & 1.03 \\
\hline 3 & 444.356 & 439.090 & 1.01 & 619.142 & 609.200 & 1.02 & 863.444 & 839.840 & 1.03 \\
\hline 4 & 176.131 & 174.320 & 1.01 & 233.137 & 229.590 & 1.02 & 308.773 & 301.790 & 1.02 \\
\hline 5 & 88.075 & 87.520 & 1.01 & 112.003 & 110.640 & 1.01 & 142.424 & 139.750 & 1.02 \\
\hline 6 & 50.670 & 50.380 & 1.01 & 62.428 & 61.720 & 1.01 & 76.883 & 75.520 & 1.02 \\
\hline 7 & 32.002 & 31.770 & 1.01 & 38.434 & 37.970 & 1.01 & 46.147 & 45.330 & 1.02 \\
\hline 8 & 21.599 & 21.370 & 1.01 & 25.402 & 25.030 & 1.01 & 29.885 & 29.310 & 1.02 \\
\hline 9 & 15.320 & 15.080 & 1.02 & 17.703 & 17.380 & 1.02 & 20.487 & 20.030 & 1.02 \\
\hline 10 & 11.293 & 11.050 & 1.02 & 12.855 & 12.570 & 1.02 & 14.677 & 14.290 & 1.03 \\
\hline 11 & 8.584 & 8.339 & 1.03 & 9.646 & 9.383 & 1.03 & 10.890 & 10.550 & 1.03 \\
\hline 12 & 6.690 & 6.453 & 1.04 & 7.433 & 7.193 & 1.03 & 8.314 & 8.015 & 1.04 \\
\hline
\end{tabular}


Table 5: LTB loads for load case 3.

\begin{tabular}{|c|c|c|c|c|c|c|c|c|c|}
\hline \multicolumn{10}{|c|}{ Load Case $3, \mathrm{q}+0.5 \mathrm{qL}(\mathrm{kN} / \mathrm{m}), \mathrm{HEA} 300$} \\
\hline $\mathrm{L}$ & \multicolumn{1}{|c|}{ Top Flange Loading } & \multicolumn{2}{c|}{ Shear Center Loading } & \multicolumn{3}{c|}{ Bottom Flange Loading } \\
\hline$(\mathrm{m})$ & PE & LT & PE/LT & PE & LT & PE/LT & PE & LT & PE/LT \\
\hline 2 & 3373.185 & 3444.000 & 0.98 & 5599.600 & 5690.300 & 0.98 & 9302.588 & 9174.200 & 1.01 \\
\hline 3 & 712.6779 & 731.960 & 0.97 & 1159.464 & 1171.500 & 0.99 & 1884.107 & 1879.700 & 1.00 \\
\hline 4 & 248.717 & 256.510 & 0.97 & 392.602 & 400.010 & 0.98 & 619.264 & 621.480 & 1.00 \\
\hline 5 & 113.4849 & 117.460 & 0.97 & 173.481 & 177.280 & 0.98 & 265.230 & 267.020 & 0.99 \\
\hline 6 & 61.03693 & 63.460 & 0.96 & 90.474 & 92.760 & 0.98 & 134.211 & 135.470 & 0.99 \\
\hline 7 & 36.64491 & 38.290 & 0.96 & 52.795 & 54.390 & 0.97 & 76.144 & 77.200 & 0.99 \\
\hline 8 & 23.7883 & 24.980 & 0.95 & 33.400 & 34.570 & 0.97 & 46.944 & 47.800 & 0.98 \\
\hline 9 & 16.36516 & 17.270 & 0.95 & 22.451 & 23.340 & 0.96 & 30.823 & 31.520 & 0.98 \\
\hline 10 & 11.77253 & 12.470 & 0.94 & 15.817 & 16.500 & 0.96 & 21.260 & 21.820 & 0.97 \\
\hline 11 & 8.773271 & 9.320 & 0.94 & 11.568 & 12.100 & 0.96 & 15.254 & 15.710 & 0.97 \\
\hline 12 & 6.727768 & 7.163 & 0.94 & 8.721 & 9.149 & 0.95 & 11.304 & 11.680 & 0.97 \\
\hline
\end{tabular}

Table 6: LTB loads for load case 4.

\begin{tabular}{|c|c|c|c|c|c|c|c|c|c|}
\hline \multicolumn{10}{|c|}{ Load Case $4, \mathrm{q}+\mathrm{qL}(\mathrm{kN} / \mathrm{m}), \mathrm{HEB} 320$} \\
\hline $\mathrm{L}$ & \multicolumn{1}{|c|}{ Top Flange Loading } & \multicolumn{2}{c|}{ Shear Center Loading } & \multicolumn{3}{c|}{ Bottom Flange Loading } \\
\hline$(\mathrm{m})$ & PE & LT & PE/LT & PE & LT & PE/LT & PE & LT & PE/LT \\
\hline 2 & 3850.613 & 3834.600 & 1.00 & 6426.753 & 6376.600 & 1.01 & 10715.661 & 10193.000 & 1.05 \\
\hline 3 & 862.414 & 852.290 & 1.01 & 1383.629 & 1345.900 & 1.03 & 2218.049 & 2152.000 & 1.03 \\
\hline 4 & 315.437 & 309.390 & 1.02 & 484.437 & 470.600 & 1.03 & 744.263 & 714.440 & 1.04 \\
\hline 5 & 149.310 & 145.920 & 1.02 & 220.155 & 213.530 & 1.03 & 324.952 & 311.790 & 1.04 \\
\hline 6 & 82.641 & 80.700 & 1.02 & 117.539 & 114.050 & 1.03 & 167.355 & 160.870 & 1.04 \\
\hline 7 & 50.749 & 49.570 & 1.02 & 69.949 & 67.890 & 1.03 & 96.484 & 92.870 & 1.04 \\
\hline 8 & 33.544 & 32.780 & 1.02 & 44.989 & 43.720 & 1.03 & 60.358 & 58.190 & 1.04 \\
\hline 9 & 23.415 & 22.880 & 1.02 & 30.667 & 29.810 & 1.03 & 40.158 & 38.770 & 1.04 \\
\hline 10 & 17.047 & 16.650 & 1.02 & 21.865 & 21.250 & 1.03 & 28.033 & 27.090 & 1.03 \\
\hline 11 & 12.831 & 12.520 & 1.02 & 16.156 & 15.700 & 1.03 & 20.334 & 19.650 & 1.03 \\
\hline 12 & 9.921 & 9.660 & 1.03 & 12.290 & 11.930 & 1.03 & 15.218 & 14.700 & 1.04 \\
\hline 13 & 7.845 & 7.619 & 1.03 & 9.577 & 9.280 & 1.03 & 11.690 & 11.280 & 1.04 \\
\hline
\end{tabular}

Table 7: LTB loads for load case 5.

\begin{tabular}{|c|c|c|c|c|c|c|c|c|c|}
\hline \multicolumn{10}{|c|}{ Load Case 5, P+P $(\mathrm{kN}), \mathrm{HEM} 360$} \\
\hline $\mathrm{L}$ & \multicolumn{2}{|c|}{ Top Flange Loading } & \multicolumn{2}{c|}{ Shear Center Loading } & \multicolumn{3}{c|}{ Bottom Flange Loading } \\
\hline$(\mathrm{m})$ & PE & LT & PE/LT & PE & LT & PE/LT & PE & LT & PE/LT \\
\hline 3 & 8279.879 & 7842.200 & 1.06 & 12173.522 & 11282.000 & 1.08 & 17912.686 & 16886.000 & 1.06 \\
\hline 4 & 4313.750 & 3909.100 & 1.10 & 6008.874 & 5471.500 & 1.10 & 8378.242 & 7838.100 & 1.07 \\
\hline 5 & 2672.884 & 2468.900 & 1.08 & 3564.170 & 3312.300 & 1.08 & 4754.544 & 4385.400 & 1.08 \\
\hline 6 & 1834.968 & 1692.400 & 1.08 & 2362.059 & 2173.800 & 1.09 & 3039.924 & 2809.700 & 1.08 \\
\hline 7 & 1347.059 & 1240.500 & 1.09 & 1684.678 & 1559.800 & 1.08 & 2105.895 & 1945.500 & 1.08 \\
\hline 8 & 1036.460 & 947.850 & 1.09 & 1265.508 & 1171.500 & 1.08 & 1544.695 & 1436.400 & 1.08 \\
\hline 9 & 825.609 & 755.480 & 1.09 & 987.848 & 910.730 & 1.08 & 1182.349 & 1089.100 & 1.09 \\
\hline 10 & 675.374 & 615.120 & 1.10 & 794.191 & 726.490 & 1.09 & 935.186 & 860.700 & 1.09 \\
\hline 11 & 564.215 & 511.090 & 1.10 & 653.562 & 595.520 & 1.10 & 759.148 & 693.930 & 1.09 \\
\hline
\end{tabular}


Table 8: LTB loads for load case 6.

\begin{tabular}{|c|c|c|c|}
\hline \multicolumn{4}{|c|}{ Load Case 6, M (kNm), HEM240 } \\
\hline L & \multicolumn{2}{|c|}{ Shear Center Loading } \\
\hline$(\mathrm{m})$ & PE & LT & PE/LT \\
\hline 3 & 3840.801 & 3644.100 & 1.05 \\
\hline 4 & 2649.359 & 2512.100 & 1.05 \\
\hline 5 & 2030.806 & 1913.100 & 1.06 \\
\hline 6 & 1654.873 & 1568.200 & 1.06 \\
\hline 7 & 1402.569 & 1319.400 & 1.06 \\
\hline 8 & 1221.383 & 1137.800 & 1.07 \\
\hline 9 & 1084.757 & 1008.500 & 1.08 \\
\hline 10 & 977.877 & 900.460 & 1.09 \\
\hline
\end{tabular}

The maximum difference between analytical solutions and 1D finite element solutions in which beams are modeled with their exact geometries becomes $10 \%$. At the end of study, it can be concluded that proposed techniques can be safely used to evaluate the elastic critical LTB loads of European HEA, HEB and HEM beams.

\section{Conclusion}

In this study, an analytical model is introduced to determine the elastic critical lateral-torsional buckling load of doubly-symmetric I-section beams. The analytical model includes effects of first-order moment gradient and load position. A closed-form equation is developed using analytical solutions and buckling parameters. Load case parameter of presented equation is calculated for six different load cases by considering three loading positions those are top flange, shear center and bottom flange and expressed as a function of a dimensionless slenderness. After slenderness of wide flange I-section beam is determined from section properties of the beam, load case parameter can be obtained for considered loading case and load position. Finally, LTB load can be calculated by substituting load case parameter into presented equation. Analytical solutions are validated with finite element analysis. It is found out that analytical solutions are in good agreement with finite element solutions. Consequently, it is concluded that presented equation can be used for calculation of the elastic critical LTB loads of HEA, HEB and HEM beams.

\section{References}

[1] N. S. Trahair, Flexural-Torsional Buckling of Structures. CRC Press, 1993.

[2] S. P. Timoshenko and J. Gere, Theory of Elastic Stability. McGraw-Hill, 1963.

[3] T. V. Galambos and A. E. Surovek, Structural Stability of Steel: Concepts and Applications for Structural Engineers, John Wiley and Sons, 2008.

[4] S. Kitipomchai, P. F. Dux, and N. J. Richter, "Buckling and bracing of cantilevers," J. Struct. Eng., vol. 110, no. 9, pp. 2250-2262, 1984.

[5] S. Kitipornchai, C. M. Wang, and N. S. Trahair, "Buckling of monosymmetric I-beams under moment gradient," $J$. Struct. Eng., vol. 112, no. 4, pp. 781-799, Apr. 1986.

[6] M. Assadi and C. W. Roeder, "Stability of continuously restrained cantilevers," J. Eng. Mech., vol. 111, no. 12, pp. 1440-1456, Dec. 1985.

[7] A. Chajes, Principles of Structural Stability Theory. Prentice-Hall, 1974.

[8] F. Bleich, H. H. Bleich, and L. B. Ramsey, Buckling Strength of Metal Structures, 1st ed. New York: McGraw-Hill, 1952.

[9] M. A. Serna, A. López, I. Puente, and D. J. Yong, "Equivalent uniform moment factors for lateral-torsional buckling of steel members," J. Constr. Steel Res., vol. 62, pp. 566-580, 2006.

[10] B. Suryoatmono and D. Ho, "The moment-gradient factor in lateral-torsional buckling on wide flange steel sections," J. Constr. Steel Res., vol. 58, pp. 1247-1264, 2002.

[11] R. S. Barsoum and R. H. Gallagher, "Finite element analysis of torsional and torsional-flexural stability problems," Int. J. Numer. Methods Eng., vol. 2, no. 3, pp. 335-352, 1970.

[12] G. J. Hancock and N. S. Trahair, "Finite element analysis of the lateral buckling of continuously restrained beam- 
columns," Inst Eng Aust Civ Eng Trans, vol. CE 20, no. 2, pp. 120-127, 1978.

[13] M. A. Bradford and H. R. Ronagh, "Generalized elastic buckling of restrained I-beams by FEM," J. Struct. Eng., vol. 123, no. 12, pp. 1631-1637, 1997.

[14] J. P. Papangelis, N. S. Trahair, and G. J. Hancock, "Elastic flexural-torsional buckling of structures by computer," Comput. Struct., vol. 68, no. 1-3, pp. 125-137, 1998.

[15] L. Haengsoo, J. Dong-Won, J. Jin-Ho, and I. Seyoung, "Finite element analysis of lateral buckling for beam structures," Comput. Struct., vol. 53, no. 6, pp. 1357-1371, 1994.

[16] J. S. Park, J. M. Stallings, and Y. J. Kang, "Lateral-torsional buckling of prismatic beams with continuous topflange bracing," J. Constr. Steel Res., vol. 60, no. 2, pp. 147-160, 2004.

[17] N. H. Lim, N. H. Park, Y. J. Kang, and I. H. Sung, "Elastic buckling of I-beams under linear moment gradient," Int. J. Solids Struct., vol. 40, no. 21, pp. 5635-5647, 2003.

[18] J. X. Gu and S. L. Chan, "A refined finite element formulation for flexural and torsional buckling of beam-columns with finite rotations," Eng. Struct., vol. 27, no. 5, pp. 749-759, 2005.

[19] H. R. Naderian and H. R. Ronagh, "Buckling analysis of thin-walled cold-formed steel structural members using complex finite strip method," Thin-Walled Struct., vol. 90, pp. 74-83, 2015.

[20] S. Ádány and B. W. Schafer, "Generalized constrained finite strip method for thin-walled members with arbitrary cross-section: Primary modes," Thin-Walled Struct., vol. 84, pp. 150-169, 2014.

[21] H. C. Bui, "Buckling analysis of thin-walled sections under general loading conditions," Thin-Walled Struct., vol. 47, no. 6-7, pp. 730-739, 2009.

[22] H. C. Bui, "Semi-analytical finite strip method based on the shallow shell theory in buckling analysis of coldformed sections," Thin-Walled Struct., vol. 50, no. 1, pp. 141-146, 2012.

[23] R. Aydin, A. Gunaydin, N. Kirac, and H. Ozbasaran, "On the Evaluation of Critical Lateral Buckling Loads of Prismatic Steel Beams," Steel Compos. Struct., vol. 3, pp. 1-21, 2013.

[24] F. Mohri, A. Brouki, and J. C. Roth, "Theoretical and numerical stability analyses of unrestrained, monosymmetric thin-walled beams," J. Constr. Steel Res., vol. 59, pp. 63-90, 2003.

[25] H. Ozbasaran, R. Aydin, and M. Dogan, "An alternative design procedure for lateral-torsional buckling of cantilever I-beams," Thin-Walled Struct., vol. 90, pp. 235-242, 2015.

[26] B. Kim, L.-Y. Li, and A. Edmonds, "Analytical solutions of lateral-torsional buckling of castellated beams," Int. J. Struct. Stab. Dyn., vol. 16, no. 8, p. 1550044, 2016.

[27] E. Mohammadi, S. S. Hosseini, and M. S. Rohanimanesh, "Elastic lateral-torsional buckling strength and torsional bracing stiffness requirement for monosymmetric I-beams," Thin-Walled Struct., vol. 104, pp. 116-125, 2016.

[28] F. Mohri, N. Damil, and M. Potier-Ferry, "Buckling and lateral buckling interaction in thin-walled beam-column elements with mono-symmetric cross sections," Appl. Math. Model., vol. 37, no. 5, pp. 3526-3540, 2013.

[39] E. Magnucka-Blandzi, "Critical state of a thin-walled beam under combined load," Appl. Math. Model., vol. 33, no. 7, pp. 3093-3098, 2009.

[30] M. Kucukler, L. Gardner, and L. Macorini, "Flexural-torsional buckling assessment of steel beam-columns through a stiffness reduction method," Eng. Struct., vol. 101, 2015.

[31] T.-T. Nguyen, P. T. Thang, and J. Lee, "Flexural-torsional stability of thin-walled functionally graded open-section beams," Thin-Walled Struct., vol. 110, no. May 2016, pp. 88-96, 2017.

[32] S. L. Chan, "Buckling analysis of structures composed of tapered members," J. Struct. Eng., vol. 116, no. 7, pp. 1893, 1990.

[33] B. Y. Yang, A. M. Asce, and J. Yau, "Stability of beams with tapered I-sections," J. Eng. Mec., vol. 113, no. 9, pp. 1337-1357, 1988.

[34] W. Bin Yuan, B. Kim, and C. Y. Chen, "Lateral-torsional buckling of steel web tapered tee-section cantilevers," $J$. Constr. Steel Res., vol. 87, pp. 31-37, 2013.

[35] A. Andrade and D. Camotim, "Lateral-torsional buckling of prismatic and tapered thin-walled open beams: Assessing the influence of pre-buckling deflections," Steel Compos. Struct., vol. 4, no. 4, pp. 281-301, 2004.

[36] A. Andrade and D. Camotim, "Lateral-torsional buckling of singly symmetric tapered beams: theory and applications," J. Eng. Mech., vol. 131, no. 6, pp. 586-597, 2005.

[37] A. Andrade, D. Camotim, and P. B. Dinis, "Lateral-torsional buckling of singly symmetric web-tapered thin-walled I-beams: 1D model vs. shell FEA,” Comput. Struct., vol. 85, no. 17-18, pp. 1343-1359, 2007. 
[38] A. Andrade, P. Providência, and D. Camotim, "Elastic lateral-torsional buckling of restrained web-tapered Ibeams," Comput. Struct., vol. 88, no. 21-22, pp. 1179-1196, 2010.

[39] A. B. Benyamina, S. A. Meftah, F. Mohri, and E. M. Daya, "Analytical solutions attempt for lateral torsional buckling of doubly symmetric web-tapered I-beams," Eng. Struct., vol. 56, pp. 1207-1219, 2013.

[40] N. Kirac, T. Yilmaz, "A Parametric study on lateral torsional buckling of European IPE and IPN beams," in Procedings of the Fifteenth International Conference on Civil, Structural and Environmental Engineering Computing, Civil-Comp Press, Stirlingshire, UK, 2015, CCP: 108. 